\title{
Quality and Readability of Web-based Arabic Health Information on Denture Hygiene: An Infodemiology Study
}

\author{
Mohammed N Alhajj ${ }^{1}$, Mohammed Mashyakhy ${ }^{2}$, Zaihan Ariffin ${ }^{3}$, Zuryati Ab-Ghani ${ }^{4}$, Yanti Johari ${ }^{5}$, Nurul S Salim ${ }^{6}$
}

\begin{abstract}
Aim: This study aimed to assess the quality and readability of the available health information on the net regarding denture hygiene. Materials and methods: Three search engines (Google, Yahoo!, and Bing) were searched. The first 20 consecutive websites from each engine were obtained and checked for eligibility. For the quality of the websites, the Health on the Net Foundation Code of Conduct (HONcode), the DISCERN tool, the Journal of the American Medical Association (JAMA) Benchmarks, and Google PageRank were used for the assessment of the included websites. For readability, an online web tool was used, including well-known analyzing indices [Flesch Kincaid grade level (FKGL), Simple Measure of Gobbledygook (SMOG), and Flesch Reading Ease (FRE)]. The acceptable readability level was set to be $\geq 80.0$ for the FRE and $<7$ for the FKGL and SMOG. The data were presented in frequencies and percentages.

Results: Out of the 60 screened websites, 14 websites were eligible for analysis. There was only one (7.1\%) website that had the HONcode seal. The mean score of all websites based on the DISCERN tool was $29.6 \pm 12.1$, with no website achieved the high score ( $\geq 65)$. Only one (7.1\%) website scored $>5$ based on Google PageRank. Regarding JAMA benchmarks, all websites achieved a mean score of 2.57 \pm 1.1 . The mean grade level based on the FKGL was $8.4 \pm 6.3$. All websites had a score of $<7$ according to the SMOG index. The mean score of the readability ease index was $90.5 \pm 16.4$.

Conclusion: Most of the dental health information on denture hygiene available on the Arabic websites did not have the required level of quality, regardless of being readable and comprehensible by most of the general people.

Clinical significance: Directing the patients to the appropriate websites related to their cases is the responsibility of the dentists.

Keywords: Denture hygiene, Health information, Infodemiology, Internet-based information, Quality assessment, Readability.

The Journal of Contemporary Dental Practice (2020): 10.5005/jp-journals-10024-2918
\end{abstract}

\section{INTRODUCTION}

Removable prosthesis is one of the most complicated scenarios in dental practice, as it requires more cooperation between dentist and patient as well as long-term maintenance and self-care. Good denture hygiene is an important factor in maintaining healthy oral mucosa among denture wearers. ${ }^{1}$ On the other hand, poor denture hygiene has been reported in the dental literature. ${ }^{2-5}$ The contributing factors for such behavior might be incomplete oral hygiene instructions given by dentists, complex anatomic characteristics of the denture which might decrease the ability to maintain good denture hygiene, the available commercial products are not efficient, and possibly among elderly patients where the manual abilities decrease. ${ }^{6-8}$ Insufficient or incomplete instructions provided by the patient's dentist may lead the patient to seek another source to get the required or additional information regarding his or her situation. ${ }^{9}$

The World Wide Web or the Internet has become the largest source of information worldwide. The current estimates of Internet users exceed two billion worldwide. Among the US adult users, around $70 \%$ search online for health information. As a result, access to health information has increased exponentially. As for patients, having some information and some simple guidelines of treatment for their cases is unarguably a positive change. On the other hand, sources of information on the net are extremely varied, ranging from an academic journal article, which contains some scientific terms that are difficult to be understood by the general public, to news and blog discussions. ${ }^{10,11}$ Health information on the net
${ }^{1,3-6}$ Prosthodontics Unit, School of Dental Sciences, Health Campus, Universiti Sains Malaysia, Kelantan, Malaysia

${ }^{2}$ Department of Restorative Dental Science, College of Dentistry, Jazan University, Jazan, Kingdom of Saudi Arabia

Corresponding Author: Zaihan Ariffin, Prosthodontics Unit, School of Dental Sciences, Health Campus, Universiti Sains Malaysia, Kelantan, Malaysia, Phone: +60199872046, e-mail: zaihan@usm.my

How to cite this article: Alhajj MN, Mashyakhy M, Ariffin Z, et al. Quality and Readability of Web-based Arabic Health Information on Denture Hygiene: An Infodemiology Study. J Contemp Dent Pract 2020;21(9): 956-960.

Source of support: Universiti Sains Malaysia

Conflict of interest: None

should be qualified, reliable, and readable. Hence, it will be difficult for the general public who search for health information to judge the quality of a website. ${ }^{12,13}$

Scientific articles published in Arabic language are scarce in the literature. Subsequently, qualified Arabic websites containing health information are few. Published articles investigating the quality and readability of the health information on the Arabic websites are also few. ${ }^{14-18}$ Moreover, up to date, no published articles have been found pertaining to the quality and readability of the dental health information on Arabic websites. The aim of this study, therefore, was to assess the quality and readability of the Arabic websites on dental health information about denture hygiene.

(-) The Author(s). 2020 Open Access This article is distributed under the terms of the Creative Commons Attribution 4.0 International License (https://creativecommons. org/licenses/by-nc/4.0/), which permits unrestricted use, distribution, and non-commercial reproduction in any medium, provided you give appropriate credit to the original author(s) and the source, provide a link to the Creative Commons license, and indicate if changes were made. The Creative Commons Public Domain Dedication waiver (http://creativecommons.org/publicdomain/zero/1.0/) applies to the data made available in this article, unless otherwise stated. 


\section{Materials and Methods}

The search was conducted on April 30, 2020. Google Chrome version 81.0.4044.138 (Official Build) (64-bit) was used for the search purpose. Before commencing the search, the cookies were erased from the browser. Moreover, browsing was done using Incognito browsing mode. The following engines were searched: "Google (http://www.google.com)," "Yahoo! (http://www.yahoo.com)," and "Bing (http://www.bing.com)."

The first 20 consecutive websites (the first 2 consecutive pages) from each engine were obtained and were checked for duplicates. Websites that presented health information on denture cleaning in the Arabic language were selected for further evaluation. Any website with the following criteria: (1) language other than Arabic; (2) presenting information on denture cleaning just by hints, audio, or video; (3) scientific articles or textbooks related to denture cleaning; (4) discussion forums; (5) sites require ID and password for access; and (6) news and social media were excluded. After that, the included websites were assessed for quality and readability. The different stages of the search strategy are shown in Flowchart 1.

The Health on the Net Foundation Code of Conduct (HONcode), ${ }^{19}$ the DISCERN tool, ${ }^{20}$ the Journal of the American Medical Association (JAMA) Benchmarks, ${ }^{21}$ and Google PageRank were used for the assessment of the included websites. The HONcode is a stamp-like seal, valid for 1 year only, displayed on the website that fulfilled specific requirements. The DISCERN is a questionnaire-based tool including 3 sections: the first section (questions 1-8) is related to the reliability of the website, the second section (questions 9-15) is related to the treatment, and the last section is question 16 that measures the overall quality of the website. The scoring system of this tool is ranging from 1 to 5 . For the overall assessment, the questions from 1 to 15 are summed. The JAMA benchmarks evaluate the authorship, attribution, disclosure, and currency of the website. The scoring system of this tool is either 0 or 1 for each criterion and from 0 to 4 for the overall. The online tool "https:// www.prchecker.info/check_page_rank.php" was used to analyze the Google PageRank. According to Google: PageRank works by counting the number and quality of links to a page to determine $a$ rough estimate of how important the website is. The scoring system is ranging from 0 to 10 .

The readability of the included websites was assessed using an online tool, "http://www.online-utility.org/english/readability_ test_and_improve.jsp" This tool was designed to analyze the readability of the English text; however, it can be used for other languages as indicated in the website. On the other hand, before starting the study, the validity of this tool was tested using Arabic texts with different levels of difficulty (simple, medium, and difficult). This website analyzes the text using different common, well-known analyzing tools [Gunning Fog Index (GFI), Coleman Liau Index (CLI), Flesch Kincaid grade level (FKGL), automated readability index (ARI), simple measure of gobbledygook (SMOG), and Flesch reading ease (FRE)]. For the analysis of the Arabic text, the GFI, $\mathrm{CLI}$, and ARI were not considered because these indices use the number of letters for readability analysis. These formulae are not applicable in the Arabic text, where the composition of the Arabic word is different than English word (the letters are linked to each other). The acceptable readability level was set to be $\geq 80.0$ for the FRE and $<7$ for the FKGL and SMOG. ${ }^{22,23}$

\section{Results}

The web search revealed a total of 3,285,600 results (Google: 3,130,000, Yahoo!: 137,000, and Bing: 18,600). Out of the 60 screened websites, 7 websites were excluded as duplicates, resulting in 53 websites analyzed for eligibility. Thirty-nine websites were excluded due to different reasons (no Arabic language, irrelevant information, News and news agency, and audio or video content). Thus, 14 eligible websites were included for quality and readability analyses (Supplementary Table).

The analysis showed that only one (7.1\%) website "www. mayoclinic.org" had the HONcode seal. The mean score of all websites based on the DISCERN tool was $29.6 \pm 12.1$. No any website achieved the high score $(\geq 65)$; however, half of the included websites ( $n=7 ; 50.0 \%$ ) had moderate score (33-64), and the remaining half $(50.0 \%)$ had low score (16-32). Based on Google PageRank, only one (7.1\%) website scored $>5$, four (28.6\%) websites scored 1 to 5 , and nine (64.3\%) websites did not achieve any score. Regarding JAMA benchmarks, all websites achieved a mean score of

Flowchart 1: Search strategy

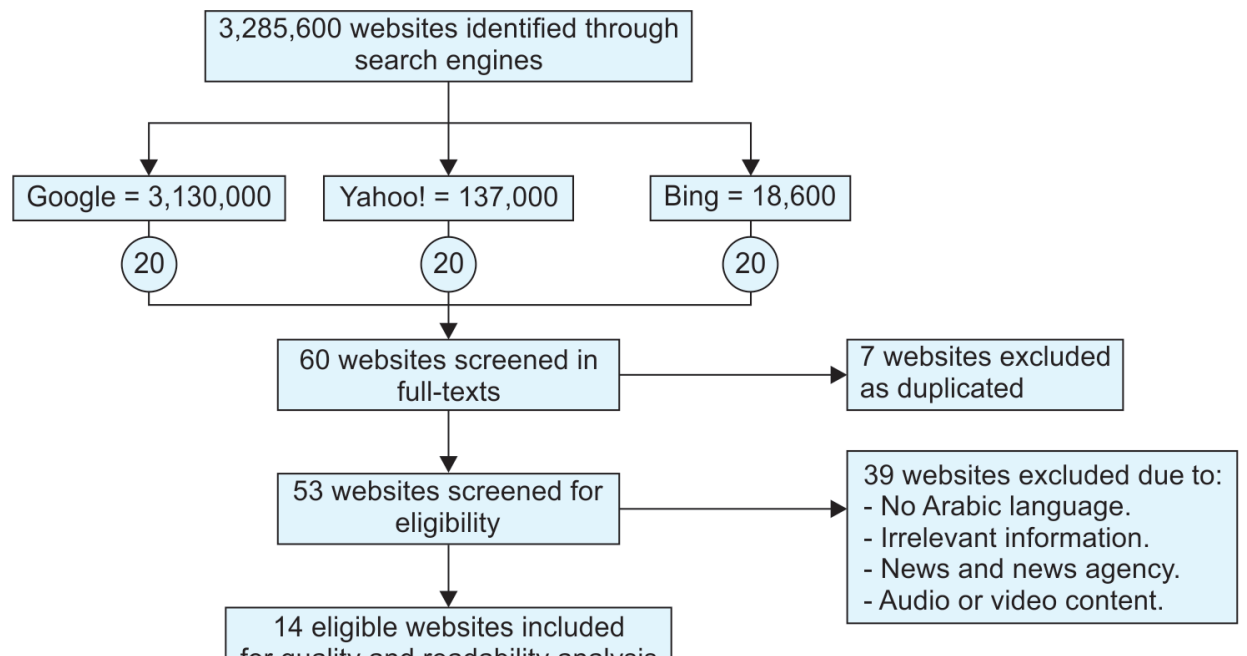
for quality and readability analysis 
$2.57 \pm 1.1$. Only $3(21.4 \%)$ websites met all items (scored 4 out of 4 ); however, three (21.4\%) websites met 1 item, three (21.4\%) websites met 2 items, and five (35.7\%) websites met 3 items. Most websites did not display references or sources for the content (Table 1).

The mean grade level based on the FKGL was $8.4 \pm 6.3$ ranging from 0.8 to 21.1. However, more than half of the included websites $(57.1 \%)$ had scores $<7$. The most difficult website to read was "www. sotor.com". According to the SMOG Index score, all websites had a score $<7$. The mean score of the readability ease, according to the FRE Index, was $90.5 \pm 16.4$ ranging from 57.6 to 110.3. Again, the website "www.sotor.com" had the most complex text (FRE = 57.6). More details are shown in Table 2. It can be noted that the HONcode-certified website "www.mayoclinic.org" had a DISCERN score of 44 (moderate score), 4 based on JAMA (met all criteria), 7 based on Google PageRank, 0.78 based on FKGL, 3 based on SMOG, and 110.34 based on FRE.

\section{Discussion}

Non-written instructions may be forgotten easily, particularly by older patients. Therefore, seeking more information from additional sources increases in such a situation. In a questionnaire-based survey conducted in the United Kingdom, around half (total $=457$ ) of the respondents (dental practitioners) stated that their patients were asking about relevant information related to their cases on the Internet. ${ }^{24}$ Unlike web-based English dental health information,

Table 1: Quality analysis of the Arabic websites $(N=14)$

\begin{tabular}{|c|c|c|}
\hline & Frequency & Percent \\
\hline \multicolumn{3}{|l|}{ HONcode } \\
\hline Certified & 1 & 7.1 \\
\hline Not certified & 13 & 92.9 \\
\hline \multicolumn{3}{|l|}{ DISCERN tool } \\
\hline High ( $\geq 65)$ & 0 & 0.0 \\
\hline Moderate (33-64) & 7 & 50.0 \\
\hline Low (16-32) & 7 & 50.0 \\
\hline \multicolumn{3}{|l|}{ Google page rank } \\
\hline$>5$ score & 1 & 7.1 \\
\hline $1-5$ score & 4 & 28.6 \\
\hline 0 score & 9 & 64.3 \\
\hline \multicolumn{3}{|l|}{ JAMA benchmarks } \\
\hline One item met & 3 & 21.4 \\
\hline Two items met & 3 & 21.4 \\
\hline Three items met & 5 & 35.7 \\
\hline Four items met & 3 & 21.4 \\
\hline \multicolumn{3}{|l|}{ Authorship-JAMA } \\
\hline 0 (not met) & 4 & 28.6 \\
\hline 1 (met) & 10 & 71.4 \\
\hline \multicolumn{3}{|l|}{ Attribution-JAMA } \\
\hline 0 (not met) & 9 & 64.3 \\
\hline 1 (met) & 5 & 35.7 \\
\hline \multicolumn{3}{|l|}{ Disclosure-JAMA } \\
\hline 0 (not met) & 2 & 14.3 \\
\hline 1 (met) & 12 & 85.7 \\
\hline \multicolumn{3}{|l|}{ Currency-JAMA } \\
\hline 0 (not met) & 5 & 35.7 \\
\hline 1 (met) & 9 & 64.3 \\
\hline
\end{tabular}

the web-based Arabic dental health information, particularly removable prostheses, are very few. This shortage is due to the progressing innovation in dental practice, including dental implants and cosmetic dentistry, so less concern is given toward removable prostheses. This infodemiology study was conducted to evaluate the available dental health information on Arabic websites about denture hygiene. In general and unsurprisingly, the quality of the web-based Arabic health information on denture hygiene was poor. Few studies in the literature have investigated the quality and readability of the web-based dental health information, and most of them were related to dental implants or orthodontics. ${ }^{25-30}$ To the best of our knowledge, this is the first infodemiology study to investigate the quality and readability of the Arabic websites regarding denture hygiene.

The first 20 consecutive websites from each search engine were selected, as the general public barely go beyond for further browsing on the net. ${ }^{31-34}$ In this study, a key phrase was used instead of a combination of more than one key words. The term "denture cleaning" is more specific and most related to the objective of the study. However, the key words "denture" and "cleaning" will result in much broader, nonspecific, and nonrelated websites. None of the included websites achieved a high score $(\geq 65)$ when assessed by the DISCERN tool. Most of the websites failed to fulfill the second section (questions 9-15) related to treatment modalities, benefits, and risks. Only one website "www.mayoclinic.org" had the HONcode seal and still valid at the time of the search. This website had a score of 44 out of 65 based on DISCERN tool, which was not the highest among other websites. However, it met all items of the JAMA benchmarks, achieved the highest score by Google PageRank, and scored the highest value of the reading ease. These higher values are obviously associated with the HONcode seal shown on this website, as this seal requires certain criteria to be fulfilled by the website.

In general, the written health information on the included websites were readable and understandable by the general public. For websites, it is advantageous to provide simple and understood text, but this should compile with the quality of this content. For patients, having more information about their cases is better; however, they might get misinformed by the available unqualified information on the net, and this may lead them to ask for more complex or inappropriate therapy. ${ }^{10,35}$ Directing the patients to or informing them about the appropriate websites related to their cases is the responsibility of the dentists. However, unfortunately,

Table 2: Readability analysis of the Arabic websites $(N=14)$

\begin{tabular}{llll}
\hline & $\begin{array}{l}\text { Flesch Kincaid } \\
\text { Grade }\end{array}$ & SMOG & $\begin{array}{l}\text { Flesch reading } \\
\text { ease }\end{array}$ \\
\hline Mean & 8.4 & 3 & 90.5 \\
SD & 6.3 & 0 & 16.4 \\
RSD & 0.7 & 0 & 0.2 \\
Median & 6.2 & 3 & 96.4 \\
Minimum & 0.8 & 3 & 57.6 \\
Maximum & 21.1 & 3 & 110.3 \\
$25-75$ IQ & 3.6 to 12.0 & 3.0 to 3.0 & 81.1 to 103.0 \\
$<7$ score & $57.1 \%(n=8)$ & $100.0 \%(n=14)$ & $\mathrm{NA}$ \\
$\geq 7$ score & $42.9 \%(n=6)$ & $0.0 \%(n=0)$ & $\mathrm{NA}$ \\
$\geq 80$ score & $\mathrm{NA}$ & $\mathrm{NA}$ & $78.6 \%(n=11)$ \\
$<80$ score & $\mathrm{NA}$ & $\mathrm{NA}$ & $21.4 \%(n=3)$ \\
\hline
\end{tabular}

$\mathrm{SD}$, standard deviation; RSD, relative standard deviation; $\mathrm{IQ}$, interquartile; NA, not applicable 
the quality of these information on the net is still unclear and need to be filtered. ${ }^{36}$

Although in the current study the News and social media websites were excluded to minimize the bias of information sources, the included websites might include some information related to commercial products or private clinics/centers. The accuracy of the written content was not investigated, although the quality of the website can refer to some extent to the quality of the written content.

\section{Conclusion}

Most of the dental health information on denture hygiene available on the Arabic websites did not have the required level of quality, regardless of being readable and understandable by most of the general people. Actions should be taken by the responsible authorities to ensure the availability of correct and reliable information on the internet.

\section{Acknowledgments}

The authors would like to acknowledge the support of Universiti Sains Malaysia (USM) Fellowship.

\section{References}

1. Kanli A, Demirel F, Sezgin Y. Oral candidosis, denture cleanliness and hygiene habits in an elderly population. Aging Clin Exp Res 2005;17(6):502-507. DOI: 10.1007/BF03327418.

2. Nagaral S, Desai RG, Kamble V, et al. Isolation of candida species from the oral cavity and fingertips of complete denture wearers. J Contemp Dent Pract 2014;15(6):712-716. DOI: 10.5005/jp-journals-10024-1604.

3. Keng SB, Lim M. Denture plaque distribution and the effectiveness of a perborate-containing denture cleanser. Quintesence Int 1996;27(5):341-345.

4. Pietrokovski J, Azuelos J, Tau S, et al. Oral findings in elderly nursing home residents in selected countries: oral hygiene conditions and plaque accumulation on denture surfaces. J Prosthet Dent 1995;73(2):136-141. DOI: 10.1016/S0022-3913(05)80152-0.

5. Abelson DC. Denture plaque and denture cleansers. J Prosthet Dent 1981;45(4):376-379. DOI: 10.1016/0022-3913(81)90094-9.

6. Kulak-Ozkan Y, Kazazoglu E, Arikan A. Oral hygiene habits, denture cleanliness, presence of yeasts and stomatitis in elderly people. J Oral Rehabil 2002;29(3):300-304. DOI: 10.1046/j.1365-2842.2002.00816.x.

7. Jeganathan S, Payne JA, Thean HP. Denture stomatitis in an elderly edentulous asian population. J Oral Rehabil 1997;24(6):468-472. DOI: 10.1046/j.1365-2842.1997.00523.x.

8. Samaranayake L. Host factors and oral candidosis. In: Samaranayake LP, McFarlane TW, ed. Oral candidosis. Bristol: Wright; 1990. pp. 66-103.

9. Seidman JJ, Steinwachs D, Rubin HR. Conceptual framework for a new tool for evaluating the quality of diabetes consumer-information web sites. J Med Internet Res 2003;5(4):e29. DOI: 10.2196/jmir.5.4.e29.

10. Fahy E, Hardikar R, Fox A, et al. Quality of patient health information on the internet: reviewing a complex and evolving landscape. Australas Med J 2014;7(1):24-28. DOI: 10.4066/AMJ.2014.1900.

11. Purcell GP, Wilson $P$, Delamothe T. The quality of health information on the internet. BMJ 2002;324(7337):557-558. DOI: 10.1136/ bmj.324.7337.557.

12. Sun Y, Zhang Y, Gwizdka J, et al. Consumer evaluation of the quality of online health information: systematic literature review of relevant criteria and indicators. J Med Int Res 2019;21(5):e12522. DOI: $10.2196 / 12522$.

13. Leaffer TR. Quality of health information on the internet. JAMA 2001;286(17):2092-2095. DOI: 10.1001/jama.286.17.2092.

14. Almaiman $\mathrm{S}$, Bahkali $S$, Alabdulatif $\mathrm{N}$, et al. Promoting oral health using social media platforms: seeking Arabic online oral health related information (OHRI). Stud Health Technol Inform 2016;226:283-286.
15. Alnemary FM, Alnemary FM, Alamri AS, et al. Characteristics of Arabic websites with information on autism. Neurosciences (Riyadh) 2017;22(2):143-145. DOI: 10.17712/nsj.2017.2.20160574.

16. Alkhateeb JM, Alhadidi MS. Information about epilepsy on the internet: an exploratory study of Arabic websites. Epilepsy Behav 2018;78:288-290. DOI: 10.1016/j.yebeh.2017.07.012.

17. Alnaim L. Evaluation breast cancer information on the internet in Arabic. J Cancer Educ 2019;34(4):810-818. DOI: 10.1007/s13187-0181378-9.

18. Alakhali MS. Quality assessment of information on oral cancer provided at Arabic speaking websites. Asian Pac J Cancer Prev 2020;21(4):961-966. DOI: 10.31557/APJCP.2020.21.4.961.

19. Boyer C, Baujard V, Geissbuhler A. Evolution of health web certification through the HONcode experience. Stud Health Technol Inform 2011;169:53-57.

20. Charnock D, Shepperd S, Needham G, et al. DISCERN: an instrument for judging the quality of written consumer health information on treatment choices. J Epidemiol Community Health 1999;53(2): 105-111. DOI: 10.1136/jech.53.2.105.

21. Silberg WM, Lundberg GD, Musacchio RA. Assessing, controlling, and assuring the quality of medical information on the internet: Caveant lector et viewor-let the reader and viewer beware. JAMA 1997;277(15):1244-1245. DOI: 10.1001/jama.1997.03540390074039.

22. Edmunds MR, Barry RJ, Denniston AK. Readability assessment of online ophthalmic patient information. JAMA Ophthalmol 2013;131(12):1610-1616. DOI: 10.1001/jamaophthalmol.2013.5521.

23. Kher A, Johnson S, Griffith R. Readability assessment of online patient education material on congestive heart failure. Adv Prev Med 2017;2017:9780317. DOI: 10.1155/2017/9780317.

24. Chestnutt IG, Reynolds K. Perceptions of how the internet has impacted on dentistry. Br Dent J 2006;200(3):161-165, discussion 149. DOI: 10.1038/sj.bdj.4813195.

25. Ali S, Woodmason $\mathrm{K}$, Patel $\mathrm{N}$. The quality of online information regarding dental implants. Br Dent J 2014;217(9):E16. DOI: 10.1038/ sj.bdj.2014.979.

26. Jayaratne YS, Anderson NK, Zwahlen RA. Readability of websites containing information on dental implants. Clin Oral Implants Res 2014;25(12):1319-1324. DOI: 10.1111/clr.12285.

27. Parekh J, Gill DS. The quality of orthodontic practice websites. Br Dent J 2014;216(10):E21. DOI: 10.1038/sj.bdj.2014.403.

28. McMorrow SM, Millett DT. Adult orthodontics: a quality assessment of internet information. J Orthod 2016;43(3):186-192. DOI: 10.1080/14653125.2016.1194599.

29. Leira-Feijoo Y, Ledesma-Ludi Y, Seoane-Romero JM, et al. Available web-based dental implants information for patients. how good is it? Clin Oral Implants Res 2015;26(11):1276-1280. DOI: 10.1111/clr.12451.

30. Barber S, Pavitt S, Meads D, et al. Assessment of information resources for people with hypodontia. BDJ Open 2018;4:18001. DOI: 10.1038/ bdjopen.2018.1.

31. Sacchetti $P, Z$ vara P, Plante MK. The internet and patient educationresources and their reliability: focus on a select urologic topic. Urology 1999;53(6):1117-1120. DOI: 10.1016/S0090-4295(98)00662-1.

32. Nguyen SK, Ingledew PA. Tangled in the breast cancer web: an evaluation of the usage of web-based information resources by breast cancer patients. J Cancer Educ 2013;28(4):662-668. DOI: 10.1007/s13187-013-0509-6.

33. Borgmann $\mathrm{H}$, Wölm JH, Vallo $\mathrm{S}$, et al. Prostate cancer on the webexpedient tool for patients' decision-making? J Cancer Educ 2017;32(1):135-140. DOI: 10.1007/s13187-015-0891-3.

34. Janssen S, Fahlbusch FB, Käsmann L, et al. Radiotherapy for prostate cancer: discern quality assessment of patient-oriented websites in 2018. BMC Urol 2019;19(1):42. DOI: 10.1186/s12894-019-0474-4.

35. Kulasegarah J, McGregor K, Mahadevan M. Quality of information on the internet-has a decade made a difference? Ir J Med Sci 2018;187(4):873-876. DOI: 10.1007/s11845-018-1790-5.

36. Benigeri $M$, Pluye P. Shortcomings of health information on the internet. Health Promot Int 2003;18(4):381-386. DOI: 10.1093/heapro/ dag409. 
Quality of Web-based Arabic Health Information on Denture Hygiene

\begin{tabular}{cl}
\multicolumn{2}{l}{ Supplementary Table } \\
\hline Index & Website link \\
\hline 1 & https://mawdoo3.com/ \\
2 & https://ar.wikihow.com/ \\
3 & https://www.thaqfya.com/clean-portable-dental-kit/ \\
4 & https://www.mayoclinic.org/ar/denture-care/expert-answers/faq-20058375 \\
5 & https://dz.dentalhealth.org/denture-cleaning \\
6 & https://www.asnanaka.com/old_man_proteza.htm \\
7 & https://www.sehatok.com/health/2018/5/9/ \\
8 & https://sotor.com/ \\
9 & https://www.elconsolto.com/dental/dental-news/details/2018/5/8/1342032/ \\
10 & https://tajmeeli.com/ \\
11 & https://www.altibbi.com/ \\
12 & https://www.magrabi.com.sa/ar/blog/the-best-way-to-keep-denture \\
13 & https://www.brightdentalcare.com.au/ar/dentures/ \\
14 & https://turkeywiz.com/ \\
\hline
\end{tabular}

